The Israeli Journal of Aquaculture - Bamidgeh, IJA_69.2017.1387, 6 pages

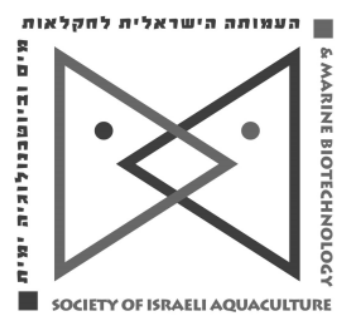

The IJA appears exclusively as a peer-reviewed on-line open-access journal at http://www.siamb.org.il. To read papers free of charge, please register online at registration form.

Sale of $I J A$ papers is strictly forbidden.

\title{
Providencia rettgeri: an Emerging Pathogen for Freshwater Cultured Whiteleg Shrimp (Penaeus vannamei)
}

\section{Chunlei Gai ${ }^{1}$, Renjian $\mathrm{Ou}^{2}$, Liqun $\mathrm{Lu}^{3}$, Xianle $\mathrm{Yang}^{3}$, Haipeng $\mathrm{Cao}^{3} *$}

1 Marine Biology Institute of Shandong, Qingdao Shandong 266104, P.R. China.

2 Longquanyi District Rural Development and Forestry Agency, Chengdu 610100, P.R. China.

${ }^{3}$ Shanghai Collaborative Innovation Center for Aquatic Animal Genetics and Breeding (ZF1206), National Pathogen Collection Center for Aquatic Animals, Shanghai Ocean University, Shanghai 201306, P.R. China.

Keywords: Providencia rettgeri; Penaeus vannamei; pathogenicity; antibiotic susceptibility.

\begin{abstract}
Bacteriosis is a major economic problem affecting the farming industry of whiteleg shrimp Penaeus vannamei. Little information is available on Providencia rettgeri as a possible pathogen for $P$. vannamei. In this study, a virulent strain, here named S6, was isolated from diseased $P$. vannamei, identified phenotypically, and molecularly, as $P$. rettgeri. A phylogenetic tree was constructed to examine the taxonomic position and relatedness of isolate $\mathrm{S} 6$ to other $P$. rettgeri isolates. When screened against a range of common veterinary antibiotics, isolate $\mathrm{S} 6$ exhibited resistance to aminoglycosides and sulfonamides antibiotics in aquaculture. To the best of our knowledge, this is the first report of $P$. rettgeri as a causal agent of bacteriosis in freshwater farmed $P$. vannamei.
\end{abstract}

* Corresponding author. e-mail: Tel: +862161900453; Fax: +862161900452; Email: hpcao@shou.edu.cn 


\section{Introduction}

Whiteleg shrimp Penaeus vannamei is widely cultivated in Central and South America, USA, East and South-East Asia, Middle East and Africa (Benzie, 2009). It is an important farming shrimp species and China's whiteleg shrimp industry has grown rapidly with a production of over 1.62 million tons in 2015 (Ministry of Agriculture of China, 2016). However, this industry has been seriously affected by bacterial diseases; these must therefore be considered when ascertaining the future development and sustainability of this industry. Studies have revealed that diseases caused by Proteus penneri, Aeromonas schubertii, and Vibrio cholerae have resulted in significant economic losses in whiteleg shrimp farms (Cao et al., 2014; Cao et al., 2015a; Cao et al., 2015b). However, very little has been reported on Providencia rettgeri infection in whiteleg shrimp.

In August 2015, a severe disease outbreak occurred in whiteleg shrimp cultured in outdoor ponds of Binzhou, Shandong province, China. The disease was highly infectious and lethal causing over $60 \%$ mortality. Diseased whiteleg shrimp suffered mainly from symptoms of septicemia. In the present study, we isolated and identified a $P$. rettgeri pathogen as a causal agent for this disease, determined its taxonomy, and antibiotic susceptibility. To our knowledge, this is the first report of $P$. rettgeri as a pathogen for whiteleg shrimp.

\section{Materials and methods}

Whiteleg shrimp samples. Thirteen diseased whiteleg shrimp averaging $9.87 \pm 0.15 \mathrm{~g}$ were sampled from infected shrimp farm ponds in Binzhou, Shandong China in August 2015. The farm had 26 acres of ponds with juvenile whiteleg shrimp stocked at an initial rearing density of 70,000 juveniles per acre. Water quality during the disease outbreak was $\mathrm{pH} 8.12,7.32 \mathrm{mg} / \mathrm{L}$ of dissolved oxygen, $0.60 \mathrm{mg} / \mathrm{L}$ of total ammonia and $0.16 \mathrm{mg} / \mathrm{L}$ of nitrite. Diseased samples were placed in sterile bags, kept in ice, and transported to the laboratory.

Isolation of Bacteria. Each sampled diseased whiteleg shrimp was surface sterilized with $75 \%$ alcohol and dissected. Samples from hepatopancreas of diseased shrimp were taken and streaked onto nutrient agar (NA) plates (Sinopharm Chemical Reagent Co., Ltd.). After incubation for $18-24 \mathrm{~h}$ at $28^{\circ} \mathrm{C}$, the most common uniform isolates were purified by streaking and re-streaking onto NA plates. Pure isolates of the dominant colonies were stored at $-80^{\circ} \mathrm{C}$ supplemented with $15 \%$ glycerol. A representative of the dominant isolates, isolate $\mathrm{S6}$, was further characterized in the present study. Examination for parasites and viruses was also conducted.

Identification of the isolate:

Molecular identification. Extraction of genomic DNA from isolate S6, as well as PCR amplification and sequencing of its 16S rRNA gene were performed according to Wang et al. (2014). The near complete 16S rRNA gene sequence was assembled using MegAlign, Editseq and Seqman software. A search was performed in the National Center for Biotechnology Information (NCBI) database for sequence homology using the Basic Local Alignment Search Tool (BLAST) program. A phylogenetic tree from the near complete 16S rRNA gene sequence of the isolate and its homologous sequences was constructed using the neighbor-joining method.

Phenotypic identification. Isolate S6 was identified phenotypically by API 32E system recommended by Shi et al. (2014). The isolate S6 was grown on NA plates (Sinopharm Chemical Reagent Co., Ltd.) at $28^{\circ} \mathrm{C}$ for $24 \mathrm{~h}$, and the bacterial suspension was then used to inoculate the Analytical Profile Index (API 32E) test strip (Biomerieux, France) following the manufacturer's instruction. The test strip was incubated at $37^{\circ} \mathrm{C}$, observed after $18 \mathrm{~h}$, and checked against the API identification index. The type strain ATCC9250 of $P$. rettgeri was used as the control.

Bacterial virulence assay. Bacterial virulence was examined by experimentally infecting healthy freshwater cultured whiteleg shrimp. One hundred healthy shrimp (averaging $6.67 \pm 0.49 \mathrm{~g}$ in weight) were obtained from Haifeng Aquaculture Co., Ltd. in Shandong China. Their health status was assessed according to the guidelines recommended by the Marine Products Export Development Authority \& Network of Aquaculture Centers in Asia-Pacific (2003). The shrimp were acclimated in ten replicate 
aquaria (each stocked with ten shrimp) containing $50 \mathrm{~L}$ of aerated filtered farming water at $28^{\circ} \mathrm{C}$ for 14 days. Prior to the bacterial virulence assay isolate S6 was inoculated onto NA plate, incubated at $28^{\circ} \mathrm{C}$ for $24 \mathrm{~h}$, and washed with normal saline into a sterile tube. Its cell density was determined by counting colony forming units after a ten-fold serial dilution in sterile distilled water. Two replicates of ten healthy shrimp were inoculated by muscular injection with $0.1 \mathrm{~mL}$ of the isolate S6 at concentrations of $2.0 \times 10^{4} \mathrm{CFU} / \mathrm{mL}$ to $2.0 \times 10^{7} \mathrm{CFU} / \mathrm{mL}$. Another two replicates of ten healthy shrimp were exposed to the same experimental conditions and injected intramuscularly with $0.1 \mathrm{~mL}$ of normal saline that served as control. The experimental shrimp were kept at $28^{\circ} \mathrm{C}$ and observed daily for five days without feeding and water change. Any dead shrimp were immediately removed and sampled to re-isolate and confirm if mortality was caused specifically by the tested isolate. The mean lethal dose $\left(\mathrm{LD}_{50}\right)$ value is calculated according to the graphical probit method as recommended by Ogbuagu \& Iwuchukwu (2014).

Antimicrobial susceptibility assay. The antibiotic sensitivity of isolate S6 was assayed on NA plates using the Kirby-Bauer disk diffusion method as described by Jones et al. (2001). Fourteen antibiotic discs were acquired from Hangzhou Binhe Microorganism Reagent Co., Ltd. The zones of inhibition were measured after a $24 \mathrm{~h}$ incubation period at $28^{\circ} \mathrm{C}$. The antibiotic susceptibility was determined according to the manufacturer's guidelines.

\section{Results}

Identification of the isolate. A dominant isolate S6 was isolated from the diseased freshwater farmed shrimp and identified as $P$. rettgeri by molecular and phenotypic methods. Its near complete $16 \mathrm{~S}$ rRNA gene sequence $(1.5 \mathrm{~kb})$ was submitted to GenBank database and assigned accession no. KY744946. The similarity between its $16 \mathrm{~S}$ rRNA gene sequence and other $P$. rettgeri isolates in the GenBank database is $99 \%$. The phylogenetic tree confirms it as a $P$. rettgeri strain (Figure 1 ). This is also demonstrated by its phenotypic features (Table 1 ) with a correlation of $96.88 \%$ compared to the reference strain. No parasites and viruses were detected in the diseased whiteleg shrimp from which the isolate S6 was obtained.

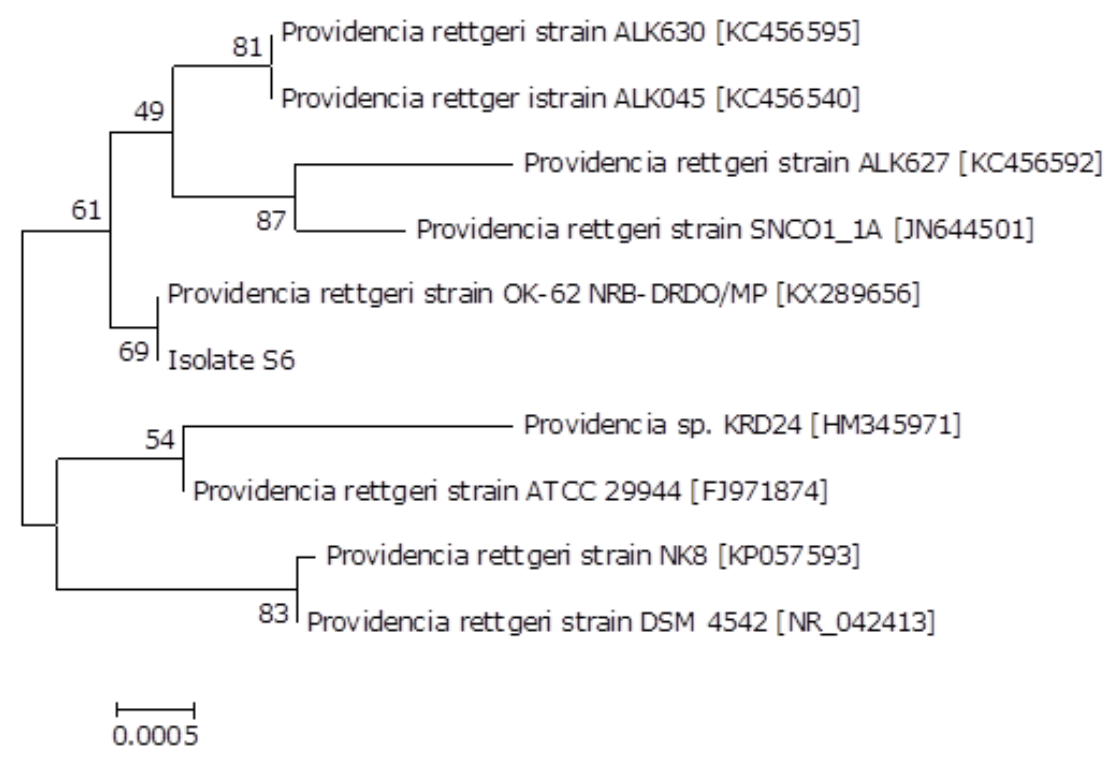

Fig. 1. The $16 \mathrm{~S}$ rRNA phylogenetic tree of 9 known bacteria and the S6 isolate constructed using neighbor-joining method. The bootstrap values (\%) are shown besides the clades, accession numbers are indicated beside the name of strains, and scale bars represent distance values. 
Table 1. Phenotypic characterization of the S6 isolate and the type strain ATCC9250 of $P$. rettgeri

\begin{tabular}{|c|c|c|}
\hline \multirow{2}{*}{ Tests } & \multicolumn{2}{|c|}{ Reaction } \\
\hline & 56 & ATCC9250 \\
\hline Arginine dihydrolase & $\mathrm{R}^{-}$ & $\mathrm{R}^{-}$ \\
\hline Lysine decarboxylase & $\mathrm{R}^{-}$ & $\mathrm{R}^{-}$ \\
\hline Lipase & $\mathrm{R}^{-}$ & $\mathrm{R}^{-}$ \\
\hline L-aspartate aminase & $\mathrm{R}^{+}$ & $\mathrm{R}^{+}$ \\
\hline$N$-acetyl- $\beta$-glucosaminidase & $\mathrm{R}^{-}$ & $\mathrm{R}^{-}$ \\
\hline$\alpha$-galactosidase & $\mathrm{R}^{-}$ & $\mathrm{R}^{-}$ \\
\hline a-glucosaccharase & $\mathrm{R}^{-}$ & $\mathrm{R}^{-}$ \\
\hline$\alpha$-maltosidase & $\mathrm{R}^{-}$ & $\mathrm{R}^{-}$ \\
\hline$\beta$-galactosidase & $\mathrm{R}^{-}$ & $\mathrm{R}^{-}$ \\
\hline$\beta$-glucosaccharase & $\mathrm{R}^{-}$ & $\mathrm{R}^{-}$ \\
\hline$\beta$-glucuronidase & $\mathrm{R}^{-}$ & $\mathrm{R}^{-}$ \\
\hline Urease & $\mathrm{R}^{+}$ & $\mathrm{R}^{+}$ \\
\hline Orinithine decarboxylase & $\mathrm{R}^{-}$ & $\mathrm{R}^{-}$ \\
\hline Indole production & $\mathrm{R}^{-}$ & $\mathrm{R}^{+}$ \\
\hline Malonate utilization & $\mathrm{R}^{-}$ & $\mathrm{R}^{-}$ \\
\hline \multicolumn{3}{|l|}{ Acid production from } \\
\hline Adonitol & $\mathrm{R}^{+}$ & $\mathrm{R}^{+}$ \\
\hline Galacturonic acid & $\mathrm{R}^{-}$ & $\mathrm{R}^{-}$ \\
\hline Inositol & $\mathrm{R}^{+}$ & $\mathrm{R}^{+}$ \\
\hline L-arabinose & $\mathrm{R}^{-}$ & $\mathrm{R}^{-}$ \\
\hline L-arabitol & $\mathrm{R}^{+}$ & $\mathrm{R}^{+}$ \\
\hline L-rhamnose & $\mathrm{R}^{+}$ & $\mathrm{R}^{+}$ \\
\hline D-arabitol & $\mathrm{R}^{+}$ & $\mathrm{R}^{+}$ \\
\hline D-cellobiose & $\mathrm{R}^{-}$ & $\mathrm{R}^{-}$ \\
\hline D-glucose & $\mathrm{R}^{+}$ & $\mathrm{R}^{+}$ \\
\hline D-maltose & $\mathrm{R}^{-}$ & $\mathrm{R}^{-}$ \\
\hline D-mannitol & $\mathrm{R}^{+}$ & $\mathrm{R}^{+}$ \\
\hline D-sorbitol & $\mathrm{R}^{-}$ & $\mathrm{R}^{-}$ \\
\hline D-sucrose & $\mathrm{R}^{-}$ & $\mathrm{R}^{-}$ \\
\hline D-trehalose & $\mathrm{R}^{-}$ & $\mathrm{R}^{-}$ \\
\hline 5-ketone-potassium gluconate & $\mathrm{R}^{-}$ & $\mathrm{R}^{-}$ \\
\hline Palatinose & $\mathrm{R}^{-}$ & $\mathrm{R}^{-}$ \\
\hline Sodium pyruvate & $\mathrm{R}^{+}$ & $\mathrm{R}^{+}$ \\
\hline
\end{tabular}

$\mathrm{R}^{+}$: positive reaction; $\mathrm{R}^{-}$: negative reaction.

Isolate S6 was virulent to whiteleg shrimp with a $L_{50}$ value of $1.52 \times 10^{5} \mathrm{CFU} / \mathrm{mL}$ (Table 2). The infected shrimp exhibited symptoms of septicemia similar to those seen in the original diseased shrimp (Figure 2). When shrimp were inoculated with a concentration of $2.0 \times 10^{7} \mathrm{CFU} / \mathrm{mL}$, acute mortality was observed. The isolate $\mathrm{S} 6$ could also be re-isolated from the dead shrimp after inoculation. No clinical signs or mortality were noted in the control shrimp.

Table 2. Cumulative mortality of experimental whiteleg shrimp infected by the isolate S6.

\begin{tabular}{|c|c|c|c|c|c|c|c|c|c|}
\hline \multirow[t]{2}{*}{ Group } & \multirow[t]{2}{*}{$\begin{array}{l}\text { Concentration } \\
(\mathrm{CFU} / \mathrm{mL})\end{array}$} & \multirow[t]{2}{*}{$\begin{array}{l}\text { Shrimp } \\
\text { no. }\end{array}$} & \multicolumn{5}{|c|}{$\begin{array}{l}\text { Nr.dead shrimp } \\
\text { on day after } \\
\text { inoculation }\end{array}$} & \multirow{2}{*}{$\begin{array}{l}\text { Average } \\
\text { cumulative } \\
\text { mortality (\%) }\end{array}$} & \multirow[t]{2}{*}{$\begin{array}{l}L D_{50} \text { value } \\
\text { (CFU/mL) }\end{array}$} \\
\hline & & & 1 & 2 & 3 & 4 & 5 & & \\
\hline Control & 0 & $\begin{array}{l}10 \\
10\end{array}$ & $\begin{array}{l}0 \\
0\end{array}$ & $\begin{array}{l}0 \\
0\end{array}$ & $\begin{array}{l}0 \\
0\end{array}$ & $\begin{array}{l}0 \\
0\end{array}$ & $\begin{array}{l}0 \\
0\end{array}$ & 0 & \\
\hline Treatment 1 & $2.0 \times 10^{4}$ & 10 & 0 & 0 & 0 & 2 & 0 & 15 & \\
\hline Treatment 2 & $2.0 \times 10^{5}$ & $\begin{array}{l}10 \\
10\end{array}$ & $\begin{array}{l}1 \\
0\end{array}$ & $\begin{array}{l}2 \\
2\end{array}$ & $\begin{array}{l}1 \\
1 \\
2\end{array}$ & $\begin{array}{l}0 \\
1\end{array}$ & $\begin{array}{l}0 \\
0\end{array}$ & 45 & $1.52 \times 10^{5}$ \\
\hline Treatment 3 & $2.0 \times 10^{6}$ & $\begin{array}{l}10 \\
10\end{array}$ & $\begin{array}{l}1 \\
2\end{array}$ & 2 & $\begin{array}{l}4 \\
3\end{array}$ & $\begin{array}{l}2 \\
2\end{array}$ & $\begin{array}{l}1 \\
0\end{array}$ & 95 & \\
\hline Treatment 4 & $2.0 \times 10^{7}$ & $\begin{array}{l}10 \\
10\end{array}$ & 2 & $\begin{array}{l}3 \\
3\end{array}$ & $\begin{array}{l}4 \\
5\end{array}$ & 1 & 0 & 100 & \\
\hline
\end{tabular}




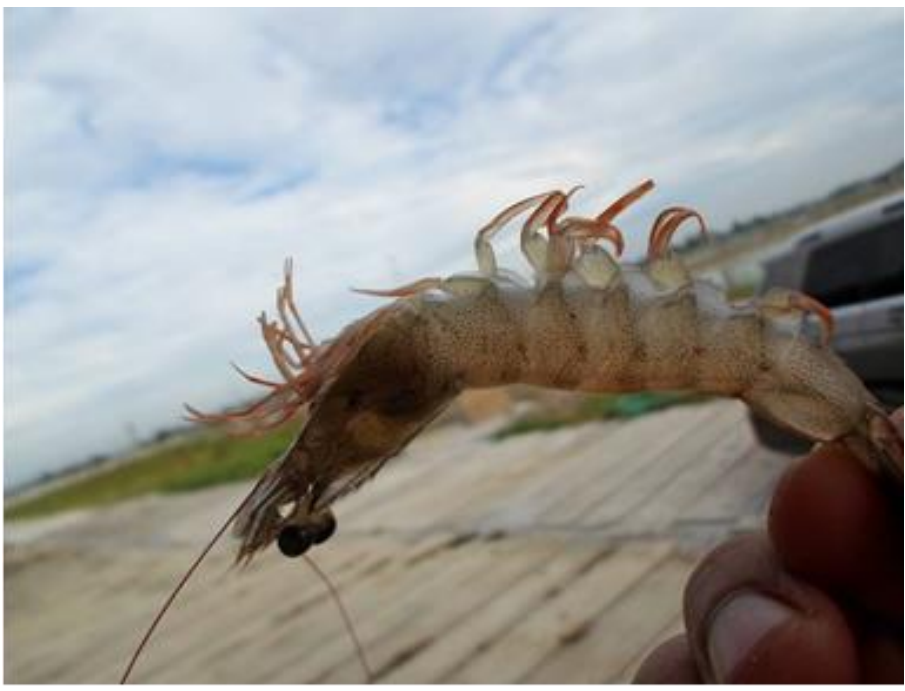

Figure 2. Gross signs of affected shrimp in the disease outbreak region.

Antibiotic susceptibility of the isolate. Antibiotic susceptibility of isolate S6 is shown in Table 3. Data indicate that isolate S6 is sensitive to enrofloxacin, florfenicol, ofloxacin, and resistant to other tested antibiotics. This suggests that isolate $\mathrm{S} 6$ has multiple resistance and has developed resistance to aminoglycosides and sulfonamides antibiotics for aquaculture use.

Table 3. Susceptibility of the S6 isolate to antibiotics.

\begin{tabular}{|c|c|c|}
\hline Antibiotics & $\begin{array}{l}\text { Content } \\
(\mu g / \text { disc })\end{array}$ & $\begin{array}{l}\text { Inhibition zone diameter } \\
(\mathrm{mm})\end{array}$ \\
\hline Ampicillin & 10 & $0 \pm 0^{R}$ \\
\hline Amikacin & 30 & $0 \pm 0^{R}$ \\
\hline Cotrimoxazole* & 300 & $0 \pm 0^{R}$ \\
\hline Enrofloxacin* & 10 & $26.85 \pm 1.17^{\mathrm{S}}$ \\
\hline Erythromycin & 15 & $12.76 \pm 0.21^{R}$ \\
\hline Florfenicol $^{*}$ & 75 & $18.61 \pm 0.68^{\mathrm{s}}$ \\
\hline Furazolidone & 300 & $0 \pm 0^{R}$ \\
\hline Gentamycin & 10 & $0 \pm 0^{R}$ \\
\hline Kanamycin & 30 & $0 \pm 0^{R}$ \\
\hline Neomycin ${ }^{*}$ & 30 & $0 \pm 0^{R}$ \\
\hline Ofloxacin & 5 & $33.95 \pm 2.11^{\mathrm{s}}$ \\
\hline Streptomycin & 300 & $0 \pm 0^{R}$ \\
\hline Sulfametoxydiazine* & 5 & $0 \pm 0^{R}$ \\
\hline Tetracycline & 30 & $0 \pm 0^{R}$ \\
\hline
\end{tabular}

${ }^{\text {S}}$ Susceptible; ${ }^{R}$ Resistant. ${ }^{*}$ Veterinary medicine for aquaculture use.

\section{Discussion}

Documentation of the connection between $P$. rettgeri and shrimp diseases is scarce. In this study, we characterized the phenotype, taxonomic position, and antibiotic susceptibility of $P$. rettgeri S6 and confirmed the pathogenicity of $P$. rettgeri to freshwater farmed $P$. vannamei.

$P$. rettgeri is an opportunistic pathogen with the ability to produce enzymatic virulence factors such as protease, gelatinase, lipase, and hemolysin (Wang et al., 2005). Diseases caused by $P$. rettgeri are usually associated with the production of these virulence factors. In the present study, $P$. rettgeri $\mathrm{S} 6$ caused $\mathrm{LD}_{50}$ mortality in healthy $P$. vannamei when inoculated with a concentration of $1.52 \times 10^{5} \mathrm{CFU} / \mathrm{mL}$. This further demonstrates the potential threat of the $\mathrm{S} 6$ isolate to whiteleg shrimp farming. Apart from the virulence of the S6 isolate, there may be other secondary factors that induce this infection in $P$. vannamei, such as the handling methods and the presence of poultry feces in rich pond water (Ramkumar et al., 2014); these should also be raised as concerns. 
The development of antimicrobic resistance in pathogenic bacteria is a matter of serious concern (Chander et al., 2006). Antibiotic resistance in $P$. rettgeri has been reported in aquaculture as a result of extensive use of antibiotics. High resistance of a $P$. rettgeri pathogen from diseased $P$. sinensis to aminoglycoside, sulfonamide, and tetracycline antibiotics has been reported (Fan et al. 2001). In our study P. rettgeri S6 also developed resistance to aminoglycosides (neomycin) and sulfonamide (cotrimoxazole, sulfametoxydiazine) antimicrobials used in shrimp farming regions, suggesting that outbreak of this disease may have resulted from abuse of antibiotics.

In conclusion, for the first time, the present study reports a $P$. rettger isolate as an emerging pathogen for freshwater cultured $P$. vannamei. The pathogenicity, and multiple drug resistance of the $\mathrm{S} 6$ isolate support the claim that this infection is an emerging threat in whiteleg shrimp farming.

\section{Acknowledgments}

This work has been financially supported by an earmarked fund for Modern AgroIndustry Technology Research System, P.R. China (No. CARS-47).

\section{References}

Benzie J.A.H., 2009. Use and exchange of genetic resources of penaeid shrimps for food and aquaculture. Rev Aquacult 1: 232-250.

Cao H., He S., Lu L., Yang X., Chen B., 2014. Identification of a Proteus penneri isolate as the causal agent for the red body disease of the cultured white shrimp Penaeus vannamei and its control with Bdellovibrio bacteriovorus. Antonie van Leeuwenhoek, 105:423-430.

Cao H., An J., He S., Lu L., Yang X., Zheng W., 2015a. Aeromonas schubertii: a potential pathogen for the freshwater cultured whiteleg shrimp Penaeus vannamei. Isr. J. Aquacult.-Bamidgeh, [IJA 67.2015.1104].

Cao H., Wen L., He S., Lu L., Yang X., Chen B., 2015b. Vibrio cholerae: a causal agent for the white feces syndrome in freshwater cultured whiteleg shrimp (Penaeus vannamei). Isr. J. Aquacult.-Bamidgeh, [IJA 67.2015.1212].

Chander Y., Goyal S.M., Gupta S.C., 2006. Antimicrobial resistance of Providencia spp. isolated from animal manure. The Veterinary Journal, 172: 188-191.

Fan H., Huang G., Guo A., Lu C., 2001. The viscera abscess of soft-shelled turtle caused by Providencia rettgeri. J Nanjing Agricult Univ 24(4): 71-74.

Jones R.N., Ballow C.H., Biedenbach D.J., 2001. Multi-laboratory assessment of the linezolid spectrum of activity using the Kirby-Bauer disk diffusion method: Report of the Zyvox@ antimicrobial potency study (ZAPS) in the United States. Diagn Microbiol Infect Dis 40:59-66.

Marine Products Export Development Authority, Network of Aquaculture Centres in Asia-Pacific, 2003. Shrimp Health Management Extension Manual. MPEDA house, Cochin, India. pp23.

Ministry of Agriculture of China, 2016. China Fishery Statistical Yearbook. Beijing: China Agriculture Press, pp28-30.

Ogbuagu D.H., Iwuchukwu E.I., 2014. Evaluation of toxicity of three hair shampoos on the catfish (Clarias gariepinus) fingerlings. Appl Ecol \& Environ Sci 2(3):86-89.

Ramkumar R., Ravi M., Jayaseelan C., Rahuman A.A., Anandhi M., Rajthilak C., Perumal P., 2014. Description of Providencia vermicola isolated from diseased Indian major carp, Labeo rohita. Aquaculture, 420-421: 193-197.

Shi L., Liang S., Shima A., Yamasaki S., Yan H., 2014. Isolation, determination and antibiotic resistant of food-born Providencia spp. Mod Food Sci Technol 37: 103-111.

Wang Z., Cai J., Xu L., Yang J., Zhang X., 2005. Studies on extracellular virulent factors produced by potential pathogenic bacteria isolated from abalone postlarvae and biofilms. Acta Microbiologica Sinica, 45(4):634-637.

Wang X., Wang J., Hao H., Qiu L., Liu H., Chen S., Dang R., Yang Z., 2014. Pathogenic Providencia alcalifaciens strain that causes fatal hemorrhagic pneumonia in piglets. Current Microbiol 68: 278-284. 